\title{
Nutrition and immunity in cancer
}

\author{
Roxana Valdés-Ramos* and Alejandra D. Benítez-Arciniega \\ Facultad de Medicina, Universidad Autónoma del Estado de México, Jesús Carranza esq. Paseo Tollocan, Col. Moderna de la \\ Cruz, Toluca, Estado de México, 50180, Mexico
}

The purpose of this article is to give a general overview of the effects of nutrition on the development of cancer as well as part of a therapeutic approach. There is much evidence that diet and lifestyle can alter the risk of cancer development as is the case for many other chronic diseases. This may be through a direct action on the immune system, either by enhancing or suppressing it, as well as on the development of the tumour itself, by modulating gene expression or by antioxidant activity. Protective effects can be achieved by adequate intakes of vitamins A and C, $\beta$-carotene, selenium and $n-3$ fatty acids among others, while negative effects are found mainly with high intakes of $n$ - 6 and saturated fatty acids. Weight gain, obesity and lack of regular physical activity have also been associated with an increased risk of cancer. The protective effects are best observed when adequate diet and lifestyle are present together. With respect to the therapeutic role of nutrition in cancer, it has been observed that the use of pre- or post-operative enteral or parenteral nutrition may improve patients' survival rates and quality of life; however, more research is needed in this particular area. Breast, colon, rectum, prostate, stomach and lung are the types of cancer most commonly associated with diet or dietary components.

Nutrition: Immunity: Cancer

A cancerous cell is one which has changed its morphology as well as its function. In particular it has lost the ability that all cells have to control their own growth, either by apoptosis or by decreasing their reproduction rate. Mutations and resulting changes in cell morphology occur throughout an individual's life-time. An intact immune system should be able to destroy cancer cells as soon as they appear. Cancer as a disease appears when the immune system is not capable of maintaining the organism's surveillance.

The association between nutrition and cancer is bi-directional and very complex. Components of foods have been found to induce mutagenic changes or, conversely, to protect against mutagenic factors or to improve the efficiency of the immune system. Once a cancerous process has started in an individual, food and nutrition may exert an important effect on the growth or involution of the tumour.

\section{The beginnings of cancer}

Cancer is typically a disease of old age and the increase in life expectancy in most countries, and particularly in developed ones, is clearly increasing the incidence of most types of cancers $^{1}$. Patterns of the disease are not fully explained by known risk factors. Much progress has been made in understanding the molecular basis of carcinogenesis, particularly the near consensus that virtually all cancers arise from an accumulation of genetic mutations and the more recent recognition of the role of inflammation and the tissue microenvironment, in particular for hormone-dependant cancers. However, most genetic mutations that contribute to cancer are not inherited, and thus must be attributable to accumulation of somatic mutations and epigenetic changes, from as yet poorly understood environmental factors, that certainly cannot be explained entirely by tobacco, use and arise over the course of a lifetime $^{2}$. Normal maintenance of any organism means that cells replicate by division to replace old cells and repair any damaged tissue areas. Cell division starts with DNA replication, which takes place in a normal human's lifetime approximately $10^{16}$ times. Even though the DNA replication system is extremely accurate, opportunities for errors occur and these may cause mutations. In addition to errors occurring during normal DNA replication, exposure to some chemical agents or radiation, as well as viral infections, may induce further changes in DNA. ${ }^{1}$

Cancer may develop when a cell accumulates mutations in genes related to cell multiplication and survival. These genes are either proto-oncogenes that normally help initiate and execute cell division or tumour suppressor genes that prevent mutant cell proliferation. The accumulation of mutations appears with advanced ageing of the body and if the immune system is incapable of identifying and destroying the mutated cells.

Cancerous cells replicate at a higher rate than normal cells, thus increasing the likelihood of further mutations, and some of the damaged cells may migrate to other tissues, causing metastasis or tumour growth in a tissue other than the one of origin. The longer a cancer is allowed to continue growing, the fewer the possibilities for the immune system to be able to recognise the damaged cells and destroy them. When mutated cells are few, the immune system may recognise and proceed to destroy them as it would any bacterial or viral infection. However when a cancer grows, the different damaged cells 
may be so many that the system is incapable of destroying them all and it fails in its surveillance job ${ }^{1}$.

Studies in animals have shown that epigenetic and metabolic adjustments caused by modifications in the nutritional environment during embryonic or foetal stages of development may have important effects on the genetics of cancer among other chronic diseases. Interactions between single nucleotide polymorphisms in various genes have been associated with metabolic responses to diet influencing the development of chronic diseases such as obesity, cardiovascular disease and cancer. Genetic inheritance allows individuals to develop any one of multiple phenotypes that are determined by metabolic and environmental conditions, such as nutrition ${ }^{3-5}$.

One of the most thoroughly evaluated associations between nutrition and the immune system is that related to dietary fat. Although total fat intake has been found to increase the risk of various types of cancer, it is the type of fat that has a more important effect on the immune response and consequently on cancer development ${ }^{6,7}$. Polyunsaturated fatty acids (PUFAs) have been shown to modulate cytokine production, lymphocyte proliferation, expression of surface molecules, phagocytosis, apoptosis and natural killer cell activity; these last two effects are closely related to cancer development. An increase in $n-3$ PUFAs helps control the production of proinflammatory eicosanoids as well as cytokine production $^{8}$. It has been shown in vitro that palmitic acid is able to potentiate iron-mediated toxicity in endothelial cells, causing mitochondrial dysfunction, cell death, apoptosis, and DNA mutation ${ }^{9-14}$

\section{The role of nutrition in cancer development}

The immune system, when acting as the body's primary defence against pathogens and cancer cells, utilises pro-inflammatory cytokines, as well as reactive oxygen and nitrogen species. When the production of these substances is excessive it may lead to chronic inflammation and an increased risk of cancer, as inflammation has been linked to the promotion phase of carcinogenesis, by inhibiting cell to cell communication between normal and cancer affected cells. In this case, the organism's ability to counter-attack this effect is very important to stop the production of cancerous cells. Nutrients such as zinc, selenium, vitamins $\mathrm{A}$ and $\mathrm{C}, n-3$ PUFAs and probiotics modulate the immune response or act as antioxidants, helping the immune system to work specifically against the cancerous cell and not against normal adjacent cells ${ }^{15,16}$.

Apoptosis or programmed cell death is the most important mechanism for the maintenance of normal tissues and organs. Cells that are cancerous have lost this ability to balance cell proliferation. Many dietary components may act as chemopreventive agents, interacting at the molecular and cellular level to modulate apoptosis, through selectively activating or inactivating gene expression. Although much of the recent research has been focused on identifying the specific effects of single nutrients or dietary components on gene expression, it is necessary to remember that the individual consumes a combination of nutrients within foods in the diet, and that the interaction of these components may not have the same positive or negative effect. A better understanding of these interactions may help identify the ideal combination of foods for cancer prevention. Low fibre and high red meat intakes, as well as an imbalance of $n-3$ and $n-6$ fatty acids have been associated with an increase in cancer risk ${ }^{17-19}$. Dietary components can alter gene expression and phenotypes of cells through various steps, thus influencing cancer ${ }^{20-24}$.

Epidemiologic studies have shown that 30 to $40 \%$ of all cancers may be preventable by maintaining a healthy lifestyle and adequate diet. Increasing fruit and vegetable intake may lower the risk of cancer, particularly breast, colon, rectum, prostate and lung ${ }^{25,26}$. This effect may be due to a resulting decrease in total fat intake and through an increase in vitamins and minerals such as selenium, folic acid, vitamin B12, vitamin $\mathrm{D}$, antioxidants such as carotenoids (alpha-carotene, beta-carotene, lycopene, lutein, cryptoxanthin), as well as phytochemicals (phenolic compounds, terpenoids, steroids, indoles and fibres) and pre- and probiotics ${ }^{22,27-30}$.

For instance, it has been shown that intake of selenium in pharmacological doses ( $\geq 200 \mu \mathrm{g} /$ day) may be protective against prostate, colon, and lung cancers ${ }^{31}$. Iron metabolism has also been associated to breast and colon cancer $^{32-35}$. Vitamin $\mathrm{E}$ in addition to its well known anti-oxidant functions, modulates the activity of microsomal enzymes, inhibits protein kinase $\mathrm{C}$ and induces apoptosis, thus acting on tumour growth and cellular proliferation ${ }^{36-40}$. Vitamin D has antiproliferative effects, promoting cellular differentiation similar to neoplasic processes; it has also been associated to UV-radiation protection ${ }^{41}$.

Table 1 presents a list of nutrients that have been associated with the development of different types of cancers either by enhancing the immune system or by exerting an immunosuppressive effect. It is always important to note that although some of these effects have been observed with the use of supplements, most of them are related to the intake of the foods that contain these nutrients.

\section{The role of weight in cancer risk}

As a consequence of excessive and mostly unbalanced food intakes, as well as sedentary lifestyles, overweight and obesity are increasing worldwide, thus increasing the risk for all chronic diseases, including cancer. In fact, weight related issues have also been associated with the development of various types of cancer ${ }^{42}$. There is much evidence suggesting that excess body weight is a risk factor for development and prognosis of several cancer types including cancer of the colon, breast, endometrium, kidney and oesophagus, as well as possible additional sites ${ }^{43-45}$. For instance, prostate cancer has

Table 1. Dietary components associated with cancer development or prevention

\begin{tabular}{ll}
\hline Nutrient & Type of cancer \\
\hline N-3 fatty acids & Breast, colon, rectum, prostate \\
N-6 fatty acids & Breast, prostate \\
Saturated fatty acids & Colon, rectum, breast, prostate \\
Vitamin A & Precancerous lesions \\
Vitamin C & Oral cavity, oesophagus, stomach, colon \\
$\beta-C a r o t e n e$ & Lung, stomach, breast, colon, prostate \\
Selenium & Lung, colon, rectum, prostate
\end{tabular}


been related to higher BMI and adult weight gain, while breast, ovarian and endometrial cancers have been found to be associated with excess weight and weight gain in adult life $\mathrm{f5}^{46}$. Weight loss after menopause is associated with a substantially reduced risk of breast cancer, thus suggesting that acquisition and maintenance of appropriate weight or BMI throughout adulthood may well result in an important reduction of cancer risk ${ }^{47-50}$.

\section{The role of nutrition in cancer therapy}

Most of the research that has been done in the area of nutrition and cancer is related to identifying the causes and ways of preventing the onset of a neoplasic event. However, research has also been done on the use of nutrition to improve the outcome of a patient after surgical treatment of a tumour. Enhancing immunity through diet is generally done by adding $n-3$ fatty acids, arginine, and nucleotides to an otherwise nutritionally complete formula. There are several trials suggesting that pre-operative immunonutrition improves outcomes in patients with upper gastrointestinal (GI) cancer surgery and is costeffective, as complications are reduced ${ }^{50-52}$.

Pre-operative immunonutrition may induce changes that modulate stress responses and improve the outcome of patients undergoing abdominal cancer surgery. Pre-operative enteral immunonutrition in patients with GI cancer improves nutritional status and immunity and decreases the incidence of post-operative complications and infections, by modulating inflammatory reactions. Pre-operative immunonutrition has been suggested to correct the impaired Th1/Th2 balance found in cancer ${ }^{53-57}$.

A specialised pre-operative oral formula with arginine, $n-3$ fatty acids, and RNA has been shown to be as effective as pre- and post-operative administration of immunonutrition in decreasing the incidence of post-operative infections and length of hospital stay. Pre-operative enteral nutrition has been suggested to provide better regulation of post-operative immune system restoration than parenteral nutrition. On the other hand, early post-operative enteral nutrition supplemented with arginine, omega-3 fatty acids and RNA has been proven to increase hydroxyproline synthesis and improve surgical wound healing in patients undergoing gastrectomy for cancer ${ }^{58-60}$.

\section{Conclusions}

There is much literature showing that diet and some nutritional components may help prevent the development of cancer in the long term. It is critical for health care providers to both acknowledge and apply the principles of nutrition for cancer prevention, and as part of a therapeutic regimen to improve prognosis once cancer has been diagnosed. With respect to prevention, the best option is to maintain a healthy lifestyle, following the general recommendations of the World Cancer Research Fund/American Institute for Cancer Research 1997 report $^{61}$, which have been summarised in Table 2. Unfortunately, although much research has been undertaken since these recommendations were issued, no official guidelines have been published since then. To the best of our knowledge, the WCRF/AICR are planning to issue their new report in November 2007. However, until it has been released no other recommendations can be made. With respect to the therapeutic effects of nutrition on cancer, much work is needed as there are few truly longitudinal studies to investigate these ${ }^{60}$.

The advances in the analysis and understanding of DNA sequences, RNA transcripts and metabolism through genomics, proteomics and metabolomics, will most probably allow the identification of specific geno- and phenotypes, and possibly evolve into metabolic profiling that will lead to individualised dietary therapies for cancer and other chronic diseases ${ }^{62}$. Fig. 1 shows the possible ways in which nutrition may have an effect on cancer development at all stages.

\section{Conflict of interest statement}

The authors have no conflict of interests. RVR and ADBA co-wrote the manuscript.

Table 2. World Cancer Research Fund/American Institute for Cancer Research 1997 Guidelines for the Prevention of Global Cancer

Populations to consume nutritionally adequate and varied diets, based primarily on foods of plant origin.

Population average body mass indices throughout adult life to be within the range BMI $21-23$, in order that individual BMI be maintained between 18.5 and 25 .

Populations to maintain, throughout life, an active lifestyle equivalent to a physical activity level (PAL) of at least $1 \cdot 75$, with opportunities for vigorous physical activity.

Promote year-round consumption of variety of vegetables and fruits, providing $7 \%$ or more of total energy.

A variety of starchy or protein-rich foods of plant origin, preferably minimally processed, to provide $45-60 \%$ total energy. Refined sugar to provide less than $10 \%$ total energy.

Consumption of alcohol is not recommended. Excessive consumption of alcohol to be discouraged. For those who drink alcohol, restrict it to less than $5 \%$ total energy for men and less than $2.5 \%$ total energy for women.

If eaten at all, red meat to provide less than $10 \%$ of total energy.

Total fats and oils to provide $15 \%$ to no more than $30 \%$ total energy.

Salt from all sources should amount to less than $6 \mathrm{~g} /$ day $(0.25$ ounces) for adults.

Store perishable foods in ways that minimise fungal contamination.

Perishable food, if not consumed promptly, to be kept frozen or chilled.

Establish and monitor the enforcement of safety limits for food additives, pesticides and their residues, and other chemical contaminants in the food supply

When meat and fish are eaten, encourage relatively low-temperature cooking. Do not eat charred food. Community dietary patterns to be consistent with reduction of cancer risk without the use of dietary supplements.

From: World Cancer Research Fund/American Institute of Cancer Research Diet, Nutrition and Prevention of Human Cancer: A Global Perspective London, WCRF, $1997^{61}$ 


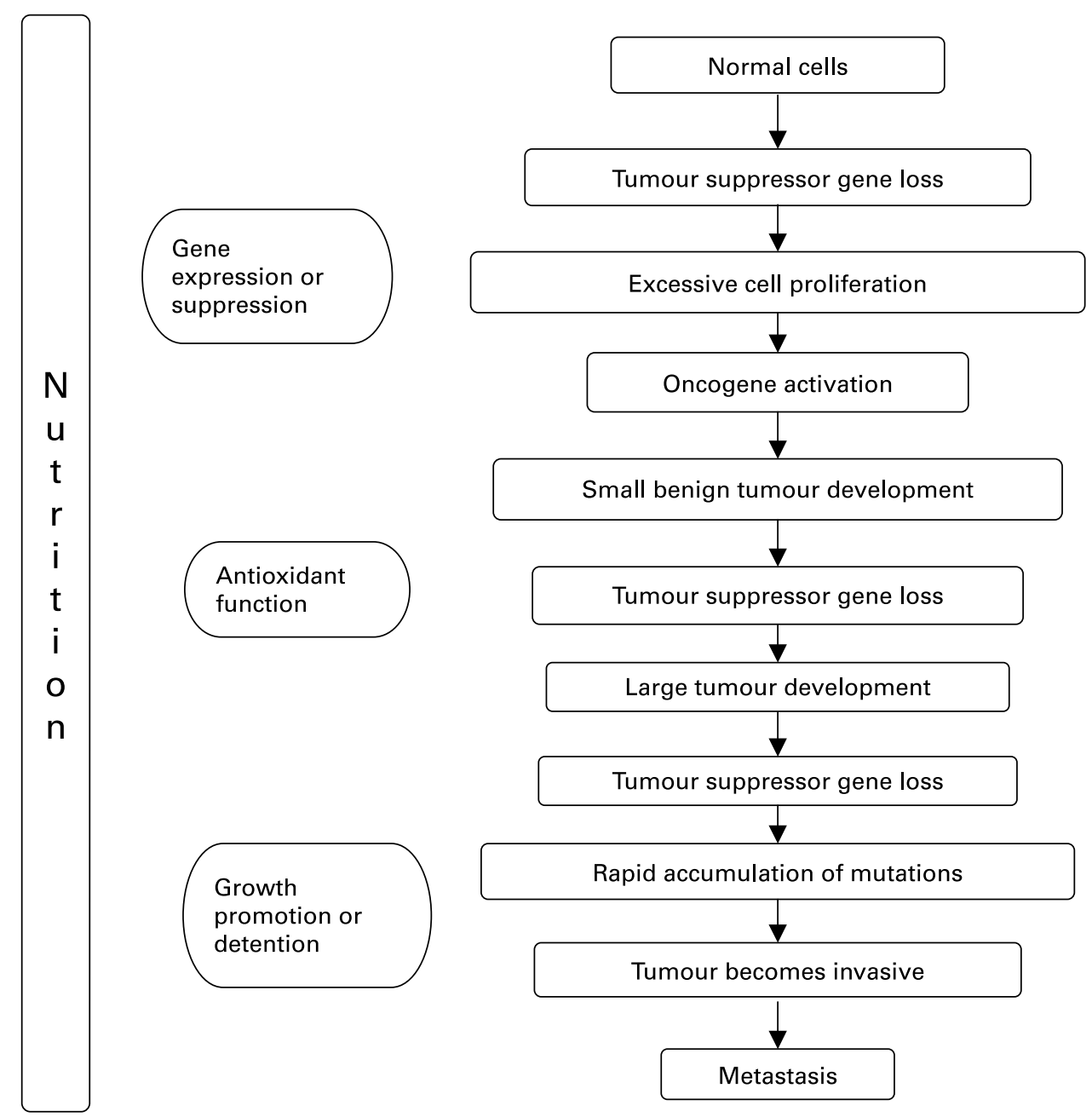

Fig. 1. Possible effects of nutrition on cancer developmental stages (Adapted from ref.1 Parham $P$ (2005)).

\section{References}

1. Parham P (2005) Cancer and interactions with the immune system. Manipulation of the immune response. In The Immune System, 2nd ed., pp. 412-430 New York: Garland Science.

2. Davis D, Donovan M, Herberman R, Gaynor M, Axelrod D, Van Larebeke N \& Sasco R, The need to develop centers for environmental oncology. doi 101016/jbiopha.2007.06.006.

3. Stover PJ \& Garza C (2006) Nutrition and developmental biology - implications for public health. Nut Rev 64, 5 Pt 2, S60-S71.

4. Ferguson IR (2006) Nutrigenomics: integrating genomic approaches into nutrition research. Mol Diagn Ther 10, 101-108.

5. Lee WN \& Go VL (2005) Nutrient-gene interactions: tracerbased metabolomics. J Nutr 132, Suppl 12, 3027S-3032S.

6. De Pablo MA, Puertollano MA \& Alvarez de Cienfuegos G (2002) Biological and clinical significance of lipids as modulators of immune system functions. Clin. Diagn. Lab Immunol. 9, 945-950.

7. Granados S, Quiles JL, Gil A \& Ramírez-Tortosa MC (2006) Dietary lipids and cancer. Nutr Hosp 21, suppl 2, 44-54.

8. Sweeney B, Puri P \& Reen DJ (2005) Modulation of immune cell function by polyunsaturated fatty acids. Pediatr Surg Int 21, 335-340.
9. Yao D, Shi W, Gou Y, Zhou X, Yee-Aw T, Zhou Y \& Liu Z (2005) Fatty acid-mediated intracellular iron translocation: a synergistic mechanism of oxidative injury. Free Radic Biol Med 39, 1305-1310.

10. Azevedo MA, Monteiro A, Lima C, Lenzen S \& Curi R (2006) Fatty acid-induced toxicity and neutral lipid accumulation in insulin-producing RINm5F cells. Toxicol In Vitro 20(7), 106-113.

11. Srivastava S \& Chan C (2007) Hydrogen peroxide and hydroxyl radicals mediate palmitate-induced cytotoxicity to hepatoma cells: relation to mithocondrial permeability transition. Free Radic Res 41(1), 38-49.

12. Borradaile N, Han X, Harp J, Gale S, Ory D \& Schaffer J (2006) Disruption of endoplasmic reticulum structure and integrity in lipotoxic cell death. J Lipid Res 47(12), 2726-2737.

13. Busch A, Guriski E, Cordery D, Sudlow M, Denver G, Laybutt D, Hughes W \& Biden T (2005) Increased fatty acid desaturation and enhanced expression of stearoyl coenzyme A desaturase protects pancreatic beta-cells from lipoapoptosis. Diabetes 54(10), 2917-2924.

14. Atshaver B, Storey S, Petrescu A, Greenberg C, Lyuksvutova O, Smith R \& Schroeder F (2002) Expression of fatty acid binding proteins inhibits lipid accumulation and alters toxicity in L cell fibrobalsts. Am J Physiol Cell Physiol. 283(3), C688-C703.

15. Philpott M \& Ferguson LR (2004) Immunonutrition and cancer. Mutat Res. 551, 29-42. 
16. Trosko JE (2006) Dietary modulation of the multistage, multimechanisms of human carcinogenesis: effects on initiated stem cells and cell-cell communication. Nutr Cancer 54, 102-110.

17. Beruin I, Min Y, Wu R, Wu J, Perry D, Cline J, Thomas M, Thornburg T, Kulik G, Smith A, Edwarrds I, D'Agostino R, Zhang H, Wu H, Kang J \& Chen Y (2007) Modulation of prostate cancer genetic risk by omega- 3 and omega- 6 fatty acids. J Clin Invest. 117(7), 1866-1875.

18. Chavarro J, Stampfer M, Li H, Campos H, Kurth T \& Ma J (2007) A prospective study of polyunsaturated fatty acid levels in blood and prostate cancer risk. Cancer Epidemiol Biomarkers Prev. 16(17), 1364-1370.

19. Neuhouser L, Barnett J, Kristal A, Ambrosone C, King I, Thornquist M \& Goodman G (2007) (n-6) PUFA increase and dairy foods decrease prostate cancer risk in heavy smokers. $J$ Nutr. 137(7), 1821-1827.

20. Davis CD \& Ross SA (2007) Dietary components impact histone modifications and cancer risk. Nutr Rev. 65, 88-94.

21. Davis CD (2007) Nutritional interactions: credentialing of molecular targets for cancer prevention. Exp Biol Med 232, $176-183$.

22. Divisi D, Di Tommaso S, Salvemini S, Garramone M \& Crisci R (2006) Diet and cancer. Acta Biomed. 77, 118-123.

23. Khan N, Afaq F \& Mukhtar H (2007) Apoptosis by dietary factors: the suicide solution for delaying cancer growth. Carcinogenesis 28, 233-239, Epub 2006 Dec 6.

24. Martin KR (2006) Targeting apoptosis with dietary bioactive agents. Exp Biol Med 231, 117-129.

25. Theodoratou E, McNeill G, Cetnarskyj R, Farrington S, Tenesa A, Barnetson R, Porteous M, Dunlop M \& Campbell H (2007) Dietary fatty acids and colorectal cancer: a case-control study. Am J Epidemiol 166(2), 181-195.

26. Kimura Y, Kono S, Toyomura K, Nagano J, Mizoue T, Moore MA, Mibu R, Tanaka M, Kakeji Y, Maehara Y, Okamura T, Ikejiri K, Futami K, Yasunami Y, Maekawa T, Takenaka K, Ichimiya H \& Imaizumi N (2007) Meat, fish and fat intake in relation to subsite-specific risk of colorectal cancer: The Fukuoka Colorectal Cancer Study. Cancer Sci 98(4), 590-597.

27. Fernandez E, Gallus S \& La Vecchia C (2006) Nutrition and cancer risk: an overview. $J$ Br Menopause Soc 12, 139-142.

28. Gonzalez CA (2006) Nutrition and cancer: the current epidemiological evidence. Br J Nutr 91, Suppl 1, 42S-45S.

29. Vainio H \& Weiderpass E (2006) Fruit and vegetables in cancer prevention. Nutr Cancer 54, 111-142.

30. Nishino H, Murakoshi M, Mou XY, Wada S, Masuda M, Ohsaka Y, Satomi Y \& Jinno K (2005) Cancer prevention by phytochemicals. Oncology 69, Suppl 1, 38S-40S, Epub 2005 Sep 19.

31. Cui Y, Vogt S, Olson N, Glass A \& Rohan T (2007) Levels of zinc, selenium, calcium, and iron in benign breast tissue and risk of subsequent breast cancer. Cancer Epidemiol Biomarkers Prev. 16(8), 1682-1685.

32. Raje D, Mukhtar H, Oshowo A \& Ingham Clark C (2007) What proportion of patients referred to secondary care with iron deficiency anemia have colon cancer? Dis Colon Rectum. 50(8), 1211-1214.

33. Kabat G, Miller A, Jain M \& Rohan T (2007) Dietary iron and heme iron intake and risk of breast cancer: a prospective cohort study. Cancer Epidemiol Biomarkers Prev. 16(6), 1306-1308.

34. Knöbel Y, Weise A, Glei M, Sendt W, Claussen U \& PoolZobel B (2007) Ferric iron is genotoxic in non-transformed and preneoplastic human colon cells. Food Chem Toxicol 45(5), 804-811.

35. Hance K, Rogers C, Hursting S \& Greiner J (2007) Combination of physical activity, nutrition, or other metabolic factors and vaccine response. Front Biosci. 12, 4997-5029.
36. Weinstein SJ, Wright ME, Lawson KA, Snyder K, Männistö S, Taylor PR, Virtamo J \& Albanes D (2007) Serum and dietary vitamin $\mathrm{E}$ in relation to prostate cancer risk. Cancer Epidemiol Biomarkers Prev. 16(6), 1253-1259.

37. Wright ME, Weinstein SJ, Lawson KA, Albanes D, Subar AF, Dixon LB, Mouw T, Schatzkin A \& Leitzmann MF (2007) Supplemental and dietary vitamin $\mathrm{E}$ intakes and risk of prostate cancer in a large prospective study. Cancer Epidemiol Biomarkers Prev. 16(6), 1128-1135.

38. Guz J, Dziaman T \& Szpila A (2007) Do antioxidant vitamins influence carcinogenesis? Postepy Hig Med Dosw (Online) 61, $185-198$.

39. Greenwald P (2007) A favorable view: progress in cancer prevention and screening. Recent Results Cancer Res. 174, 3-17.

40. Flora $S$ (2007) Role of free radicals and antioxidants in health and disease. Cell Mol Biol. 53(1), 1-2.

41. Mullin G \& Dobs A (2007) Vitamin D and its role in cancer and immunity: a prescription for sunlight. Nutr Clin Pract. 22(3), 305-322.

42. Ceschi M, Gutzwiller F, Moch H, Eichholzer M \& ProbstHensch NM (2007) Epidemiology and pathophysiology of obesity as cause of cancer. Swiss Med Wkly. 137, 50-56.

43. Wright ME, Chang SC, Schatzkin A, Albanes D, Kipnis V, Mouw T, Hurwitz P, Hollenbeck A \& Leitzmann MF (2007) Prospective study of adiposity and weight change in relation to prostate cancer incidence and mortality. Cancer 109, $675-684$.

44. Linos E, Holmes MD \& Willett WC (2007) Diet and breast cancer. Curr Oncol Rep. 9, 31-41.

45. Carmichael AR (2006) Obesity and prognosis of breast cancer. Obes Rev. 7, 333-340.

46. Han D, Nie J, Bonner MR, McCann SE, Muti P, Trevisan M, Ramirez-Marrero FA, Vito D \& Freudenheim JL (2006) Lifetime adult weight gain, central adiposity, and the risk of preand postmenopausal breast cancer in the Western New York exposures and breast cancer study. Int $J$ Cancer. 119, 2931-2937.

47. Samanic C, Chow WH, Gridley G, Jarvholm B \& Fraumeni JF $\mathrm{Jr}$ (2006) Relation of body mass index to cancer risk in 362,552 Swedish men. Cancer Causes Control. 17, 901-909.

48. Greer JB, Modugno F, Ness RB \& Allen GO (2006) Anthropometry and the risk of epithelial ovarian cancer. Cancer 106, $2247-2257$.

49. Trentham-Dietz A, Nichols HB, Hampton JM \& Newcomb PA (2006) Weight change and risk of endometrial cancer. Int J Epidemiol 35, 151-158, Epub 2005 Nov 8.

50. McCowen KC \& Bistrian BR (2003) Immunonutrition: problematic or problem solving? Am J Clin Nutr 77, 764-770.

51. Sax HC (2005) Immunonutrition and upper gastrointestinal surgery: what really matters. Nutr Clin Pract. 20, 540-543.

52. Malik A, Afaq F, Sarfaraz S, Adhami VM, Syed DN \& Mukhtar $\mathrm{H}$ (2005) Pomegranate fruit juice for chemoprevention and chemotherapy of prostate cancer. Proc Natl Acad Sci USA 102, 14813-14818, Epub 2005 Sep 28.

53. Tsujinaka T, Hirao M, Fujitani K, Mishima H, Ikenaga M, Sawamura T \& Kurata M (2007) Effect of preoperative immunonutrition on body composition in patients undergoing abdominal cancer surgery. Surg Today 37, 118-121, Epub 2007 Jan 25.

54. Xu J, Zhong Y, Jing D \& Wu Z (2006) Preoperative enteral immunonutrition improves post-operative outcome in patients with gastrointestinal cancer. World J Surg 30, 1284-1289.

55. Chen DW, Wei Fei Z, Zhang YC, Ou JM \& Xu J (2005) Role of enteral immunonutrition in patients with gastric carcinoma undergoing major surgery. Asian J Surg. 28, 121-124.

56. Matsuda A, Furukawa K, Takasaki H, Suzuki H, Kan H, Tsuruta H, Shinji S \& Tajiri T (2006) Preoperative oral immune-enhancing nutritional supplementation corrects $\mathrm{TH} 1 / \mathrm{TH} 2$ imbalance 
in patients undergoing elective surgery for colorectal cancer. Dis Colon Rectum. 49, 507-516.

57. Moskovitz DN \& Kim YI (2004) Does perioperative immunonutrition reduce postoperative complications in patients with gastrointestinal cancer undergoing operations? Nutr Rev. 62, 443-447.

58. Ates E, Yilmaz S, Erkasap S, Ihtiyar E, Kaya Y, Pehlivan T, Ustuner Z, Yasar B \& Kiper H (2004) Perioperative immunonutrition ameliorates the postoperative immune depression in patients with gastrointestinal system cancer (prospective clinical study in 42 patients). Acta Gastroenterol Belg. 67, $250-254$.
59. Farreras N, Artigas V, Cardona D, Rius X, Trias M \& Gonzalez JA (2005) Effect of early postoperative enteral immunonutrition on wound healing in patients undergoing surgery for gastric cancer. Clin Nutr. 24, 55-65.

60. Sanford K (2005) Reintroduction to nutrition and cancer treatment. Semin Oncol Nurs. 21, 164-172.

61. World Cancer Research Fund/American Institute of Cancer Research Diet (1997) Nutrition and Prevention of Human Cancer. A Global Perspective London: WCRF.

62. Go VL, Nguyen CT, Harris DM \& Lee WN (2005) Nutrientgene interaction: metabolic genotype-phenotype relationship. J Nutr 132, Suppl 12, 3016S-3020S. 